\title{
Organizational Justice and Organizational Citizenship Behavior Case Study: Rasht Public Hospitals
}

\author{
Mehrdad Goudarzvandchegini (Corresponding author) \\ Department of Public Management, Rasht Branch \\ Islamic Azad University, Rasht, Iran \\ Shahram Gilaninia \\ Department of Industrial Management, Rasht Branch \\ Islamic Azad University, Rasht, Iran \\ Tel: +98-911-335-6977_E-mail: gilani_sh45@yahoo.com
}

Rahim Abdesonboli

Medicine Science University, Guilan Branch, Iran

Tel: +98-911-333-5902Ｅ-mail: r.abdesonboli@gmail.com

Received: October 4, 2011

doi:10.5430/ijba.v2n4p42
Accepted: October 24, $2011 \quad$ Published: November 21, 2011

URL: http://dx.doi.org/10.5430/ ijba.v2n4p42

\begin{abstract}
Background: In today's competitive world, organizations are constantly seeking new ways to maximize the performance of their employees. Despite the increased use of information technology, there are still gaps in performance and efficient organization. There is strongly idea that the performance of organization largely depends to the efforts of the employees beyond the requirements of the role. These behaviors named as over duties behavior, spontaneous behavior and organizational citizenship behavior. Today, these behaviors are an integral part in performance management and have been entered in organizational various aspects. Researches show that perceived organizational justice is one of the factors that lead to citizenship behavior. Methods: In this research, we used field research technique and for gathering data collection used questionnaires. Statistical population was employees of public hospitals in Rasht that they are 2811 employees. Then, distributed 341 questionnaires based on convenience sampling. Method of research was correlation and for analyzing, we used spss software. Results: This study shows that there is a relationship among dimensions of organizational justice and organizational citizenship behavior in the Rasht public hospitals and due to positive correlation coefficients, it is the direct relationship. Conclusion/Recommendation: Finally, results show that between distributive justice, procedural justice, interactional justice and informational justice with organizational citizenship behavior there is a direct and significant relationship. i.e., with increment of each of the variables, organizational citizenship behavior will increase. In addition, coefficient level between two variables equals to 0.289 and this situation show that independent variable can predict dependent variable extent to 28.9 .
\end{abstract}

Keywords: Organizational Justice, Organizational Citizenship Behavior, Public Hospital, Iran

\section{Introduction}

Organizations in order to competition in global scene and comply customers demeans try to select which employees that doing their jobs over his duties and job description (Senobari, 2008). In the past, employees were assessing by job description and job specification but today's over duties behaviors are important. These behaviors consider as the concept of social behaviors, over duties behaviors, contextual performance, organizational citizenship behavior and spontaneous behavior. Today, these behaviors are an integral part in performance management and entered in organizational various aspects. Unlike the past that expected from staff to act in a formal role, in the new psychological contract over duties behaviors are expected. These behaviors named as organizational citizenship behavior. Researchers paid attention to the organizational citizenship behavior due to the strong results and positive effects on performance (Bolino et al., 2002; Cohen and Kol, 2004). Citizenship behavior is a behavior that is not employee's official duties but this is desirable and 
useful for organization (Neami and Shokrkon, 2004). Organs indicate that organizational citizenship behavior refers to fair and voluntary actions such as assist colleagues on working issues, polite behavior with personnel and competently described the organization to outside people which will improve the effectiveness of the organization. Organ (1998) provides a classification for dimensions of organizational citizenship behavior: Conscientious, Courtesy, Altruism, Sportsmanship, Civic virtue.

In other hand, research shows perceived organizational justice is one of the factors that cause employees doing their jobs over his duties (Colquitt et al., 2001). Studies have shown that the processes of justice can play an important role in the organization and how behavior with people may affect on beliefs, feelings, attitudes and behavior of employees. Justice can lead to employee's high commitment and over duties jobs (Yaghobi et al., 2010). Organizational justice shows that organization what doing for their staff to feel they are treate as fair with them. Organizational justice classified in four types: distributive justice, procedural justice, interactional justice and informational justice (McDowall and Fletcher, 2004).

Distributive justice: distributive justice could be defineas a receipts percived of fairness of a person in social exchanges. People, understanding the fairness based on the comparison between information and data compare them with the standards that are received (Place et al., 2010). Distributive justice is also fair observe in the interest and proficiency that a person received from organization (Moshref-Javadi et al., 2006).

Interactional justice: interactional justice implies respect and honesty in the conduct of social interactions with people (Blakely et al., 2005). In addition, the quality of behavior among persons that is feeling by someone is interactional justice (Moshref-Javadi et al., 2006). Interactional justice is a way that transfers organizational justice by supervisors to subordinates. This type of justice related to aspects of the communication process (such as politeness, honesty and respect) between the transmitter and receiver of justice (Bahari-Far and Javaheri-Kamel, 2010).

Procedural justice: Justice requires adopting fair procedures. Regardless of the basis and content of the law must be fair; that process justice is supposed to derive from it must also be fair. Justice and fairness in the procedures performed must be equal opportunity provided to everyone. Therefore, we can say that justice requires clear rules and procedures when is fair that facilities the access of everyone from law (Ramin-Mehr et al., 2009). This kind of justice is a positive correlation with organizational support, assistance and competition (Behrens, 2008).

Informational justice: informational justice refers to the behavior of the actors in transmitting information. In general, informational justice focuses on the behavior of decision makers (Colquitt et al., 2001). In other words, informational justice indicates on how the information presented in the society fairly in terms of location, time and situation.

Consideration to organizational behavior, special organizational citizenship behavior is important. Citizenship behavior is more important in the hospital because patients who need special care and positive behaviors of nurses and doctors with patients and with each others have an important role in strengthening morale and betterment of them (Mardani-Hamole and Heydari, 2009). The overall issue addressed in this study is exploring the relationship between organizational justice and organizational citizenship behavior of employees in public hospitals of Rasht. This research is seeking answers to these questions:

Is there a meaningful relationship between organizational justice and employees' organizational citizenship behavior in public hospitals of Rasht?

Is there a meaningful relationship between the components of organizational justice and employees' organizational citizenship behavior in public hospitals of Rasht?

\section{Background and Relationship}

Organs (1988) indicate that organizational citizenship behavior refers to fair and voluntary actions such as assist colleagues on working issues, polite behavior with personnel and competently described the organization to outside people which will improve the effectiveness of the organization. According to researches, the importance of organizational citizenship behavior and the relationship of this behavior with success, productivity and organizational effectiveness are considerable (Podsakoff et al., 2000). Many researchers have focused on identifying the preconditions for organizational citizenship behavior. In this regard, many variables have been identified such as job satisfaction, organizational justice, personality, leadership, role perceptions, organizational commitment and age of workers (Figure 1).

\section{$<$ Figure 1 about here $>$}

Researches show that employee perceptions of fairness in the workplace are related with a positive view of organizational citizenship behavior. Organ said that employee perceptions of justice manifested by the increase or decrease of organizational citizenship behavior. Therefore, decreasing the organizational citizenship behavior can be one answer to 
not existing of justice in organization (Abili et al., 2009). Organ (1988) believes that organizational citizenship behavior has five dimensions:

Conscientious: this behaviors guidance the individual for doing their duties in somewhat higher than expected levels.

Courtesy: indicates respectful behaviors that avoid creating the problem and difficult in the workplace, for example, a person tries to avoid create problems to colleagues or will consult with others before doing action.

Altruism: helping partners and employees to perform tasks in unusual circumstances.

Sportsmanship: emphasis on positive aspect of organization and ignore the negative aspect.

Civic virtue: are behaviors that indicate the person responsible participation related to in organization activities, for example individuals coordinate their duties with organization events or doing things that are not in the domain of duties, but raising the organizations fame.

In this study, we use this measure for organizational citizenship behavior.

Many empirical studies supported the impact of organizational justice on organizational citizenship behavior such as Guangling, 2011; Nadiri, 2010; Goudarzvand-Chegini, 2009; Bihn et al., 2005; Steve and Wongtze, 2002; and Moorman, 1991.

Therefore, due attention to above discuses can be presented the hypothesis that exist bilateral relations between these two variables and the level of individual behavior is important for development the organizational justice and the other hand, organizational justice strengthen the incidence of individuals good citizenship behaviors. The characteristic of a mutual relationship is observe mutual trust, respect and commitment and this is help to beyond the role behavior and as the role (Organ, 1988). On the other hand beyond the role behaviors or organizational citizenship behaviors that doing voluntary and does not exist formal requirement for its implementation, probably plays an important role in cross-organizational relation. Therefore, with the help of literature we can say that organizational justice will help to making organizational citizenship behavior as Figure 2.

\section{$<$ Figure 2 about here $>$}

According to conceptual model of research, main hypothesis is that there is a significant relationship between organizational justice and organizational citizenship behavior in Rasht public hospitals. In addition, sub-hypotheses are:

There is a meaningful relationship between distributive justice and organizational citizenship behavior.

There is a meaningful relationship between interactional justice and organizational citizenship behavior.

There is a meaningful relationship between procedural justice and organizational citizenship behavior.

There is a meaningful relationship between informational justice and organizational citizenship behavior.

\section{Research Methods}

Method: This study is a survey research and applicable.

Measures: Questionnaire in this study is the main tool for data collection. Data collection tools in this study are two separate questionnaires for assessing organizational justice and organizational citizenship behavior. Organizational citizenship behavior questionnaire design by composition the dimensions of Organ (1988) which also includes the twenty questions. Organizational justice questionnaire design based on previous researches. The validity of the questionnaire was approved by the previous researches. Furthermore, to test the questionnaires reliability we used Cronbach's $\alpha$ scores for each variable as shown in Table1.

\section{$<$ Table 1 about here $>$}

Statistical Population and Sample: The statistical populations of this study are the employees of all public hospitals in Rasht. They are 2811 employees and then we distributed 341 questionnaires based on convenience sampling. For calculated the sample we use the following formula:

$$
\begin{aligned}
n & =\frac{z_{\frac{k}{2}}^{2} \cdot s_{x}^{2} N}{a^{2} \cdot N-e^{2}+\left(z_{\frac{\pi}{2}}^{2} \cdot S_{x}^{2}\right)} \\
z_{\frac{k}{2}} & =1.96 \\
a & =0.05
\end{aligned}
$$


$\mathrm{N}=2811$

$\mathrm{n}=341$

$S^{2}=0.252$

$n=\frac{(1.96)^{2} \cdot(0.252) \cdot(2811)}{\left(0.05^{2}\right) \cdot(2811)-\left(0.05^{2}\right)+\left(\left(1.96^{2}\right) *(0.252)\right)}=341$

Method of research was correlation and for analyzing, we used spss software. To achieve this sample size based on convenience sampling distributed 360 questionnaires and eventually 347 questionnaires returned that after removing useless questionnaires 343 questionnaires were used for statistical analysis.

\section{Results}

Table 2 shows the characteristics of participated employees in this study. Due attention to table 2 could say that:

1) Descriptive statistics for demographic variables related to sex of interviewers shows that \%24 of employees' are men and, $\% 76$ of employees' are females.

2) Descriptive statistics for demographic variables related to age of respondent's shows that $\% 84.5$ of employees sample has over 30 years of old and age distribution of respondents indicate that a significant number of respondents faced with various public issues throughout his work life and this issue have been able to them to judge about organizational issues.

3) Descriptive statistics for demographic variables related to education shows that $\% 95$ of employees sample has college, university and postgraduate education and this indicate that most members of the sample has power of thought and rational judgments about the threads questioned.

\section{$<$ Table 2 about here $>$}

\subsection{Relationship between the Organizational Justice and Organizational Citizenship Behavior}

Based on the above relation, the main hypothesis was given test by Pearson correlation due attention to table3.

Main hypothesis: there is a significant relationship between the organizational justice and organizational citizenship behavior in the public hospital of Rasht.

The results of statistical tests of this hypothesis indicate that in a significant percentage "there is a significant relationship between the organizational justice and organizational citizenship behavior in the public hospital of Rasht". The intensity of relation between these two variables is 0.54 and this represents a direct link between them. Therefore, this hypothesis is generally confirmed with the $\% 99$ confidence level in the public hospital of Rasht. In addition, coefficient between two variables is equal 0.289 . This situation shows that the independent variable can predict the dependent variable to extent of $\% 28.9$.

$<$ Table 3 about here $>$

\subsection{Relationship between the Distributive Justice and Organizational Citizenship Behavior}

Based on the above relation, the first sub-hypothesis was given test by Pearson correlation due attention to table4.

First sub-hypothesis: there is a significant relationship between the distributive justice and organizational citizenship behavior in the public hospital of Rasht.

The results of statistical tests of this hypothesis indicate that in a significant percentage "there is a significant relationship between the distributive justice and organizational citizenship behavior in the public hospital of Rasht". The intensity of relation between these two variables is 0.43 .4 and this represents a direct link between them. Therefore, this hypothesis is generally confirmed with the $\% 99$ confidence level in the public hospital of Rasht. In addition, coefficient between two variables is equal 0.188 . This situation shows that the independent variable can predict the dependent variable to extent of $\% 18.8$.

\subsection{Relationship between the Interactional Justice and Organizational Citizenship Behavior}

Based on the above relation, the second sub-hypothesis was given test by Pearson correlation due attention to table4.

Second sub-hypothesis: there is a significant relationship between the interactional justice and organizational citizenship behavior in the public hospital of Rasht.

The results of statistical tests of this hypothesis indicate that in a significant percentage "there is a significant relationship between the interactional justice and organizational citizenship behavior in the public hospital of Rasht". The intensity of relation between these two variables is 0.42 .3 and this represents a direct link between them. Therefore, this hypothesis is 
generally confirmed with the $\% 99$ confidence level in the public hospital of Rasht. In addition, coefficient between two variables is equal 0.187 . This situation shows that the independent variable can predict the dependent variable to extent of $\% 18.7$.

\subsection{Relationship between the Procedural Justice and Organizational Citizenship Behavior}

Based on the above relation, the third sub-hypothesis was given test by Pearson correlation due attention to table4.

Third sub-hypothesis: there is a significant relationship between the procedural justice and organizational citizenship behavior in the public hospital of Rasht.

The results of statistical tests of this hypothesis indicate that in a significant percentage "there is a significant relationship between the procedural justice and organizational citizenship behavior in the public hospital of Rasht". The intensity of relation between these two variables is 0.36 and this represents a direct link between them. Therefore, this hypothesis is generally confirmed with the $\% 99$ confidence level in the public hospital of Rasht. In addition, coefficient between two variables is equal 0.128 . This situation shows that the independent variable can predict the dependent variable to extent of $\% 12.8$

\section{$<$ Table 4 about here $>$}

\subsection{Relationship between the Informational Justice and Organizational Citizenship Behavior}

Based on the above relation, the forth sub-hypothesis was given test by Pearson correlation due attention to table4.

Forth sub-hypothesis: there is a significant relationship between the informational justice and organizational citizenship behavior in the public hospital of Rasht.

The results of statistical tests of this hypothesis indicate that in a significant percentage "there is a significant relationship between the informational justice and organizational citizenship behavior in the public hospital of Rasht". The intensity of relation between these two variables is 0.43 .7 and this represents a direct link between them. Therefore, this hypothesis is generally confirmed with the $\% 99$ confidence level in the public hospital of Rasht. In addition, coefficient between two variables is equal 0.1909 . This situation shows that the independent variable can predict the dependent variable to extent of $\% 19.09$

\section{Discussion and Conclusion}

Guangling (2011) indicate that there is a positive relationship between organizational justice and organizational citizenship behavior $(r=0.41)$. In addition, Goudarzvand-Chegini (2009) had a research in a sample of 300 employees of the public organizations and shown that there is a significant relationship between organizational justice and organizational citizenship behavior $(\mathrm{r}=0 / 85)$. Moreover, there are significant relationship between distributive justice and organizational citizenship behavior $(r=0 / 69)$ and between informational justice and organizational citizenship behavior ( $r$ $=0 / 67.7)$. In the present study, results indicate that there is a positive relationship between organizational justice and organizational citizenship behavior $(\mathrm{r}=0 / 54)$.

Nadiri et al (2010) indicate that between distributive and procedural justice and organizational citizenship behavior there are a direct relationship $(\mathrm{r}=0.37)$ and $(\mathrm{r}=0.51)$, respectively.

According to the results of the test assumptions and validate the hypothesis about the relationship between organizational justice and organizational citizenship behavior $(r=0.54)$ and due attention to the relationship between organizational citizenship behavior and organizational performance and the impact of organizational citizenship behavior on increasing the flexibility of organization, enhancing the organization abilities for employee the best people, increasing the managerial productivity and other positive actions of organizational citizenship behavior expect the supply a context for creation and improving of organizational citizenship behavior. The researches indicate that when employees feel that they participate in organizational decision they believe that work terms are fairly and this situation can improve the organizational citizenship of employees.

With considering to the above texts and other researches about organizational justice and organizational citizenship behavior we could state in order to increase of organizational citizenship behavior extent in public organizations should creation the fairly climate. So, in these organizations employees should feel that there is an acceptable level all four types of organizational justice (distributive, procedural, interactive and information) in their organization.

Most participants in this study believe that distributive justice in their organization are average, however, significant levels of the respondents have pointed that this dimension of justice is low and very low. It should be noted by hospital authorities for adopt practical solutions to increase distributive justice as a proportion of work that person does with the 
salary, wage, bonus or promotional offers that are received. Always, fairness and equality in pay and bonuses are considering.

A significant number of respondents of questionnaire in response to questions about procedural justice has been expressed this dimension is low and very low. This show that low levels of procedural justice and employee dissatisfaction with the procedures and practices that are distributed output data in the organization (e.g. salary, promotion, reward, reprimand). Other researches related to justice also indicate that employees regardless of the level of education and position have been assigned to control procedures of output and they have high sensitivity toward fairness of the procedures.

It is suggested must be avoided of bias and discrimination in decision making, organizations should design some plans for considering the employees commentaries and criticisms, can provide possibility of appeal for employees who feel treated them unfairly, and in decisions related to employees ethical standards supported and increased they incentives for better performance.

Participants in this study in response to questions about interactive justice and informational justice points are to the high level of these justices in the organization. This situation indicates that there is a polite manner between supervisors and subordinates and behave with courtesy and respect with employees and provide timely information to employees that cause the over duties behavior of staff.

In this study there is not moderate variable, due attention to the results suggests using moderate variable in order to assess the relationship between organizational justice and organizational citizenship behavior such as: age, gender, education and organizational post.

\section{References}

Abili, K. H., Shateri, K., Yozbashi, A., \& Faraji-Deh Sorkhi, H. (2009). Organizational citizenship behavior: characteristics, dimensions and outcomes. $1^{\text {st }}$ National Conference of Mangement of Organizational Citizenship Behavior.

Bahari-Far, A., Javaheri-Kamel, M. (2010). The survey of outcomes of organization ethical values. Journal of Tosse Ensani Police, Vol. 7, No. 28.

Behrens, K. (2008). Investigating the High Performance Work System: Employee Perception and Employment Conditions in a Health Care Setting. World Academy of Science, Engineering and Technology, No. 43, pp. $289-303$.

Bihn, A. E., Messer, W., \& Fiona, A. (2005). Employees mood, perceptions of fairness, organizational citizenship behavior. Journal of Business and Psychology, Vol. 21, No. 1, pp. 1- 14.

Blakely, G.L., Andrews, M.C., \&Moorman, R.H. (2005). The Moderating Effects of Equity Sensitivity on the Relationship between Organizational Justice and Organizational Citizenship Behaviors. Journal of Business and Psychology, Vol. 20, No. 2, pp. 259-273. http://dx.doi.org/10.1007/s10869-005-8263-3

Bolino, M.C., Turnley, W. H., Bloodgood, J. M. (2002). Citizenship behavior and the creation of social capital in organizations. Academy of Management Review, Vol. 27, No. 4, pp. 505-522.

Cohen, A., Kol, Y. (2004). Professionalism and organizational citizenship behavior: An empirical examination among Israeli nurses. Journal of Managerial Psychology. Vol. 19, 4, pp. 386-406. http://dx.doi.org/10.1108/02683940410537945

Colquitt, J. A., Canlon, D. E., Wesson, M. J., \& Porter, C. (2001). Justice at the millennium: A meta-analytic review of 25 years of Organizational Justice research. Journal of Applied Psychology, Vol. 86, No. 3, pp. 425-445. http://dx.doi.org/10.1037/0021-9010.86.3.425

Goudarzvand-Chegini, M. (2009). The relationship between organizational justice and organizational citizenship behavior. American Journal of Economics and Business Administration, Vol. 1, No. 2, pp. 171-174.

Guangling,W. (2011). The study on relationship between employees' sense of organizational justice and organizational citizenship behavior in private enterprises. Energy Procedia, No. 5, pp. 2030-2034.

Mardani-Hamole, M., Heydari, H. (2009). The relationship between organizational justice and organizational civic behavior in hospital employees. Journal of Ethic and Medical History.

McDowall, A., Fletcher, C. (2004). Employee development: an organizational justice perspective. Personnel Review, Vol. 33, No.1, pp. 69-75. http://dx.doi.org/10.1108/00483480410510606

Moorman, R. H. (1991). The relationship between organizational justice and organizational citizenship behaviors: Do fairness perceptions influence employee citizenship? Journal of Applied Psychology, No. 76, pp. 845-855. http://dx.doi.org/10.1037/0021-9010.76.6.845

Moshref-Javadi, M. H., Dalvi, M. R., Abdolbaghi, A. (2006). Organizational justice in the shadow of Alavi justice. Journal of Modiriyate Farda, No. 15-16. 
Nadiri, H., Cem, T. (2010). An investigation of the role of justice in turnover intentions, job satisfaction, and organizational citizenship behavior in hospitality industry. International Journal of Hospitality Management, No. 29, pp. 33-41. http://dx.doi.org/10.1016/j.ijhm.2009.05.001

Neami, A., Shokrkon, H. (2004). The relationship of organizational justice and organizational civic behavior of employees in Ahvaz industrial organizations. Journal of Pyschology, No. 1-2.

Organ, D. W. (1988). Organizational Citizenship Behavior: The good Soldier Syndrome. Lexington. MA: Lexington Books.

Place, W., Ballenger, J., Wasonga, T. A., Piveral, J., \& Edmonds, C. (2010). Principals' perspectives of social justice in public schools. International Journal of Educational Management, Vol. 24, No. 6, pp. 531-543. http://dx.doi.org/10.1108/09513541011067692

Podsakoff, A., Mackenzie, E., Paine, C., \& Bachrach, G. (2000). Organizational citizenship behaviours: a critical review or theoretical and empirical literature and suggestions for future research. Journal of Management, Vol. 26, No. 3, pp. 513-563. http://dx.doi.org/10.1177/014920630002600307

Ramin-Mehr, H., Hadizadeh-Moghadam, A., Ahmadi, I. (2009). The relationship between percive of organizational justice and organizational citizenship behavior (case study: Tehran petroleum company), Journal of Change Management, Vol. 1, No. 2.

Senobari, M. (2008). Organizational citizenship behavior: definitions, dimensions and impact facor. Journal of Tosse Ensani Police, Vol. 5, No. 16

Steve, W., \& Wongtze, S. H. (2002). Mood and organizational citizenship behavior the effects of positive affect on employee organizational citizenship behavior intentions. The Journal of Psychology, Vol. 133, No.6, pp. 656 - 668.

Yaghobi, M., Javadi, M., Agha-Rahimi, Z. (2010). The relationship between knowledge management and syudents demographic characteristics in Isfahan Medical University. Iranian Journal of Education in Medical Science, Number of development and education.

Table1. Cronbach's $\alpha$ Scores

\begin{tabular}{|c|l|c|c|}
\hline Variables & Dimensions & Number of items & Cronbach $\alpha$ \\
\hline Organizational Justice & Distributive Justice & 4 & 0.84 \\
& Interactional Justice Procedural Justice & 4 & 0.92 \\
& Informational Justice & 7 & 0.72 \\
& & 5 & 0.95 \\
\cline { 2 - 4 } & Total Dimensions & 20 & 0.89 .5 \\
\hline Organizational Citizenship Behavior & & 20 & 0.72 \\
\hline
\end{tabular}

Table2. General Data of Samples In The Study

\begin{tabular}{|c|l|c|c|}
\hline \multicolumn{4}{|c|}{ Employees } \\
\hline \multirow{3}{*}{ Sex } & \multicolumn{1}{|c|}{} & Frequency & Percent \\
\hline \multirow{4}{*}{ Age } & Male & 82 & $\% 24$ \\
\cline { 2 - 4 } & Female & 261 & $\% 76$ \\
\hline \multirow{5}{*}{ Education } & Total & 343 & $\% 100$ \\
\cline { 2 - 4 } & Up to 30 & 53 & $\% 15.5$ \\
\cline { 2 - 4 } & $31-40$ & 220 & $\% 64.8$ \\
\cline { 2 - 4 } & $41-50$ & 68 & $\% 19.7$ \\
\hline \multirow{5}{*}{} & Total & 343 & $\% 100$ \\
\cline { 2 - 4 } & Diploma & 14 & $\% 4.2$ \\
\cline { 2 - 4 } & College & 63 & $\% 18.4$ \\
\cline { 2 - 4 } & University & 181 & $\% 52.4$ \\
\cline { 2 - 4 } & PH.D & 27 & $\% 7.8$ \\
\hline & Total & 58 & $\% 17.2$ \\
\hline & & 343 & $\% 100$ \\
\hline
\end{tabular}


Table3. Test of Main Hypothesis

\begin{tabular}{|c|c|c|c|c|c|}
\hline Hypothesis & Independent variable & Dependent Variable & $\mathrm{R}$ & Sig. & Result \\
\hline Main & $\begin{array}{c}\text { Organizational } \\
\text { Justice }\end{array}$ & $\begin{array}{c}\text { Organizational } \\
\text { Citizenship Behavior }\end{array}$ & 0.54 & 0.000 & Accepted \\
\hline
\end{tabular}

Table4. Test of Sub Hypotheses

\begin{tabular}{|c|c|c|c|c|c|}
\hline Sub H. & Independent variable & Dependent Variable & $\mathrm{R}$ & Sig. & Result \\
\hline 1 & Distributive Justice & $\begin{array}{c}\text { Organizational } \\
\text { Citizenship Behavior }\end{array}$ & 0.43 .4 & 0.000 & Accepted \\
\hline 2 & Interactional Justice & $\begin{array}{c}\text { Organizational } \\
\text { Citizenship Behavior }\end{array}$ & 0.42 .3 & 0.000 & Accepted \\
\hline 3 & Procedural Justice & $\begin{array}{c}\text { Organizational } \\
\text { Citizenship Behavior }\end{array}$ & 0.36 & 0.000 & Accepted \\
\hline 4 & Informational Justice & $\begin{array}{c}\text { Organizational } \\
\text { Citizenship Behavior }\end{array}$ & 0.43 .7 & 0.000 & Accepted \\
\hline
\end{tabular}

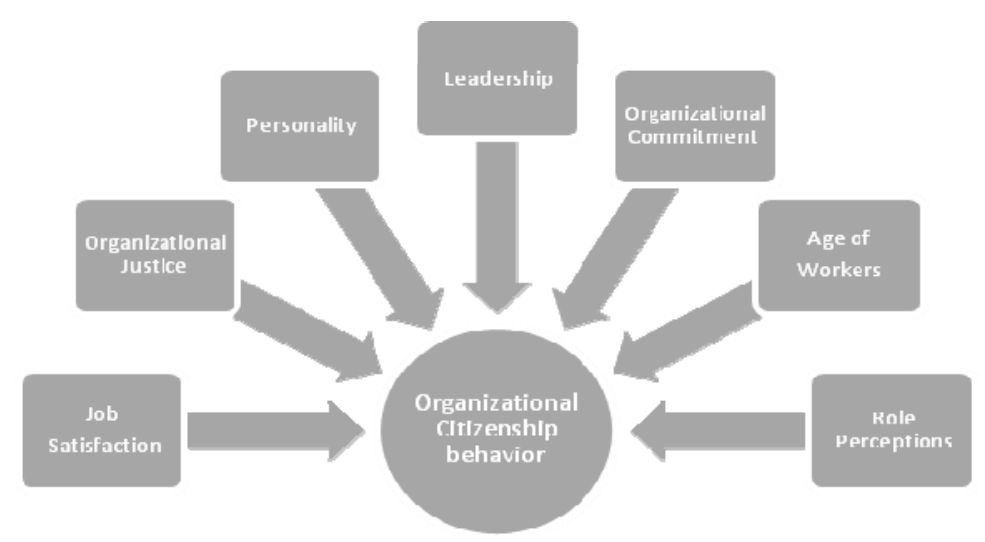

Figure 1. Preconditions of Organizational Citizenship Behavior

(Abili et al., 2009)

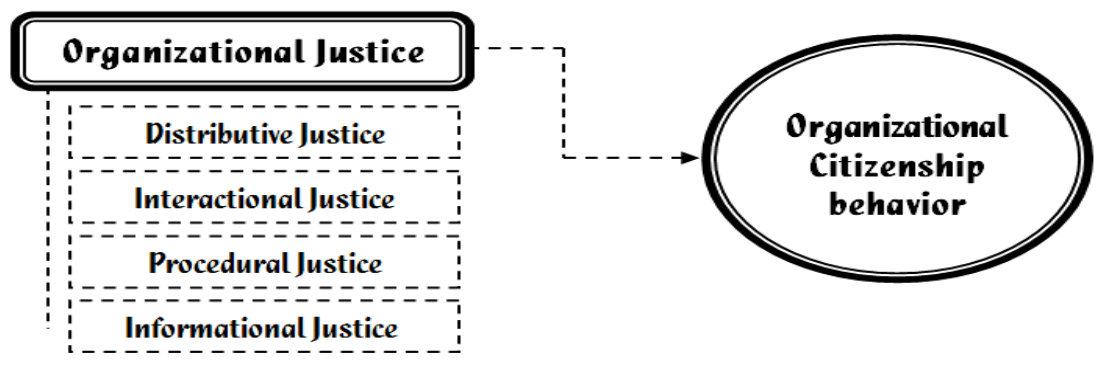

Figure 2. Conceptual Model of Research 